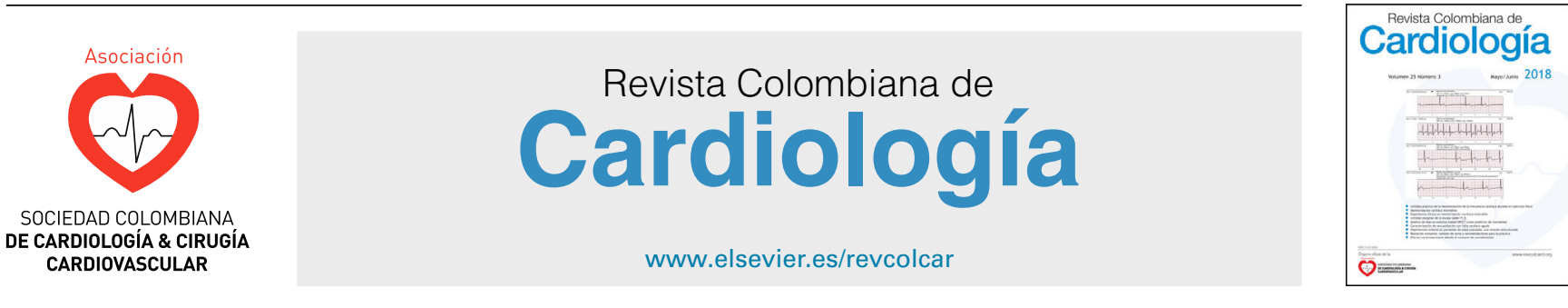

CARDIOLOGÍA DEL ADULTO - ARTÍCULO ORIGINAL

\title{
Factores asociados a la mortalidad en el primer año postrasplante cardíaco
}

\author{
Juan E. Gómez-Mesa ${ }^{\mathrm{a}, \mathrm{b}, *}$, Evelyn Peña-Zárate ${ }^{\mathrm{b}}$, Isabel L. Zapata-Vásquez ${ }^{\mathrm{b}}$, \\ Juan D. López-Ponce de León ${ }^{a, b}$, Pastor Olaya-Rojas ${ }^{a, b}$, Diana C. Carrillo-Gómez ${ }^{a, b}$, \\ Eliana Manzi-Tarapues ${ }^{b, c}$, Erika Rincón-Escobar ${ }^{c}$, Stephania Galindo-Coral ${ }^{c}$ \\ y Noel Flórez-Alarcón ${ }^{\mathrm{a}, \mathrm{b}}$
}

\author{
a Departamento de Medicina Interna, Servicio de Cardiología, Fundación Valle del Lili, Cali, Colombia \\ b Facultad de Ciencias de la Salud, Universidad Icesi, Cali, Colombia \\ c Centro de Investigaciones Clínicas, Fundación Valle del Lili, Cali, Colombia
}

Recibido el 13 de enero de 2019; aceptado el 3 de septiembre de 2019

Disponible en Internet el 16 de septiembre de 2020

\section{PALABRAS CLAVE \\ Trasplante cardiaco; Mortalidad; \\ Factores de riesgo}

\begin{abstract}
Resumen
Introducción: en el trasplante cardiaco la sobrevida es del 81 al $85 \%$ en el primer año; las infecciones y la falla del injerto son las principales causas de mortalidad.

Objetivo: determinar los factores de riesgo asociados a mortalidad al año postrasplante cardiaco en un hospital de alta complejidad del suroccidente colombiano.

Métodos: cohorte retrospectiva de pacientes con trasplante de corazón llevado a cabo entre 1996 a 2015. Se obtuvo la información de las características del donante, receptor y procedimiento quirúrgico. Se realizó una regresión de Cox; el evento de interés fue la mortalidad al primer año de seguimiento. En el análisis multivariable se incluyeron variables con $p \leq 0,20$ y significancia clínica.

Resultados: se incluyeron 158 pacientes, con mediana de edad de 50 años (RIC: 39-57), 76\% hombres. La principal etiología de falla cardiaca fue idiopática (45\%). La mediana de tiempo de isquemia fue 187 minutos (RIC: 142-300). La mortalidad fue $24 \%$, y se atribuyó principalmente a infecciones (29\%). Fueron factores asociados a mortalidad la cardiopatía congénita como etiología de falla cardíaca ( 0,048$)$, antecedente de diabetes mellitus ( 0,001$)$, cirugía cardiaca previa $(\mathrm{p} 0,023)$ tiempo de isquemia mayor a 150 minutos $(\mathrm{p} 0,038)$ y relación receptor

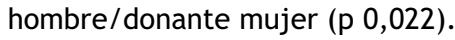

\footnotetext{
* Autor para correspondencia.

Correo electrónico: juan.gomez.me@fvl.org.co (J.E. Gómez-Mesa).
} 
Conclusiones: los factores asociados a mayor mortalidad en el primer año postrasplante cardiaco fueron: etiología de la falla cardíaca por cardiopatía congénita, antecedente de diabetes mellitus, cirugía cardiaca previa, relación receptor hombre con donante mujer, tiempo de isquemia mayor a 150 minutos.

(c) 2019 Publicado por Elsevier España, S.L.U. en nombre de Sociedad Colombiana de Cardiología y Cirugía Cardiovascular. Este es un artículo Open Access bajo la licencia CC BY-NC-ND (http:// creativecommons.org/licenses/by-nc-nd/4.0/).

\section{KEYWORDS}

Heart transplant; Mortality;

Risk factors

\section{Factors associated with mortality in the first year post-cardiac transplantation}

\begin{abstract}
Introduction: The survival rate in the first year after heart transplant is between $81 \%$ and $85 \%$. The main causes of mortality are infections and failure of the graft.

Objective: To determine the risk factors associated with mortality at one year post- cardiac transplant in a high complexity hospital in south-west Colombia.

Methods: A retrospective cohort study was performed on patients with a heart transplant carried out between 1996 and 2015. Information was obtained on the characteristics of the donor, recipient, and surgical procedure. A Cox regression was performed, with the event of interest being mortality in the first year of follow-up. In the multivariate analysis, variables were included that had a $P \leq .20$ and clinical significance.

Results: The study included a total of 158 patients, with a median age of 50 years (IQR: 39$57)$, of whom $76 \%$ were males. The most common origin was idiopathic heart failure $(45 \%)$. The median time of ischaemia was 187 minutes (IQR: 142-300). The mortality was $24 \%$ and was mainly due to infections (29\%). There were factors associated with the congenital heart failure mortality such as origin of heart failure $(P=.048)$, history of diabetes mellitus $(P=.001)$, previous cardiac surgery $(P=.023)$, ischaemia time greater than 150 minutes $(P=.038)$, and the male recipient / female donor ratio $(P=.022)$.

Conclusions: The factors associated with higher mortality in the first year post-cardiac transplant were: origin of heart failure due to congenital heart disease, history of diabetes mellitus, previous cardiac surgery, the male recipient / female donor ratio, and an ischaemia time greater than 150 minutes.

(c) 2019 Published by Elsevier España, S.L.U. on behalf of Sociedad Colombiana de Cardiología y Cirugía Cardiovascular. This is an open access article under the CC BY-NC-ND license (http:// creativecommons.org/licenses/by-nc-nd/4.0/).
\end{abstract}

\section{Introducción}

La falla cardiaca es una de las enfermedades más prevalentes en el mundo y pese a que en los últimos años la supervivencia ha mejorado, las tasas de mortalidad absolutas se mantienen alrededor del $20 \%$ en el primer año y $50 \%$ a los cinco años posteriores al diagnóstico. Es por esto que se han establecido diferentes estrategias de manejo, incluyendo dispositivos cardiovasculares implantables, dispositivos de asistencia mecánica y cirugía cardiovascular, con el fin de optimizar el estado de salud de los pacientes ${ }^{1}$. Sin embargo, existe un subgrupo de pacientes, que pese a un manejo médico óptimo, progresan y desarrollan síntomas severos, y evolucionan a insuficiencia cardiaca avanzada, refractaria o estadio $D$, en quienes una de las opciones es el trasplante cardiaco, el cual es considerado el tratamiento más adecuado en estos $\operatorname{casos}^{1,2}$.

Se estima una sobrevida en el primer año postrasplante cardíaco del 81 al 85\%; el primer mes postrasplante es el periodo más crítico para mortalidad, cuyas causas, al igual que en el primer año, son las infecciones no relacionadas a citomegalovirus (CMV) y la falla del injerto ${ }^{3}$. El desenlace a largo plazo después del trasplante ha mejorado con los avances logrados en la selección de los candidatos, en la técnica quirúrgica, la terapia de inmunosupresión y el cuidado postoperatorio ${ }^{1}$. Dado a lo anterior, en este estudio se analizaron variables propias del donante, del receptor y del procedimiento quirúrgico de los pacientes trasplantados de corazón en un centro de alta complejidad del suroccidente colombiano, con el propósito de identificar factores que influyen en la mortalidad durante el primer año postrasplante.

\section{Materiales y métodos}

Estudio de cohorte retrospectivo de pacientes sometidos a trasplante cardíaco en la Fundación Valle del Lili, institución de alta complejidad ubicada en Cali, Colombia. En esta institución se creó el registro de trasplante cardíaco (RETRAC) en el año 2015 con seguimiento postrasplante cardíaco de forma prospectiva de los pacientes con información del donante, del receptor, el protocolo pretrasplante, el evento intraoperatorio, el postoperatorio temprano, la 
estancia hospitalaria postrasplante, las complicaciones hospitalarias y el seguimiento clínico posterior al trasplante.

Antes del año 2015 la recolección de la información fue retrospectiva. Fueron elegibles los pacientes postrasplante cardíaco desde el año 1996 hasta diciembre de 2015 ingresados en el RETRAC y se incluyeron aquellos de 18 años o más, llevados a trasplante cardíaco solo o combinado, con información disponible del protocolo pretrasplante y de seguimiento hasta al menos el primer año postrasplante. Se incluyeron variables sociodemográficas del receptor y del donante, antecedentes médicos, etiología de la falla cardíaca, función renal pretrasplante, información del protocolo de trasplante y estado clínico al momento del trasplante cardíaco; además, se incluyeron variables del intraoperatorio y el postoperatorio inmediato.

Se realizó un análisis univariado de las variables cuantitativas con medidas de tendencia central y dispersión, mediante la prueba estadística de Kolmogorov-Smirnov para establecer la normalidad de las distribuciones; para las variables categóricas se realizaron tablas de frecuencia de acuerdo con el estado vital al año de seguimiento. Se compararon utilizando la prueba t de Student o WilcoxonMann-Whitney de acuerdo con el cumplimiento de supuestos para las variables cuantitativas, y para las categóricas con $\mathrm{Chi}^{2}$ o test exacto de Fisher.

Se clasificó la prioridad del trasplante al momento del llamado, así:

- 0A: aquellos que tenían soporte circulatorio para descompensación hemodinámica o choque cardiogénico y que incluyeron al menos uso de oxigenación por membrana extracorpórea (ECMO), disfunción primaria del injerto, ventilación mecánica continua, balón de contrapulsación aórtico, asistencias ventriculares de corta duración, en tormenta arrítmica, infusión continua intravenosa hospitalaria de un inotrópico a dosis altas por más de 48 horas (dobutamina a dosis mayor a 7,5 mcg/k/min o milrinona mayor o igual a 0,5 $\mathrm{mcg} / \mathrm{k} / \mathrm{min}$ ).

- OB: aquellos que requirieron uso de inotrópicos intravenosos durante más de 72 horas, con o sin monitorización hemodinámica invasiva de las presiones de llenado ventricular, levosimendan repetitivo en un plazo menor a dos semanas, intrahospitalario, o infusión continua hospitalaria de inotrópicos intravenosos a cualquier dosis por más de siete días, levosimendan repetitivo en un plazo menor a dos semanas, ambulatorio o paciente sensibilizado en terapia de desensibilización.

- Estadio 1: aquellos que no cumplieran ninguna de las anteriores.

Se construyó un modelo de riesgos proporcionales Cox con evento de interés la mortalidad en el primer año de seguimiento. Se descartaron del modelo de regresión aquellas variables que en análisis univariado tuvieron más del $20 \%$ de datos perdidos. Inicialmente, se realizó un modelo univariado y posteriormente uno multivariado en el que se incluyeron variables sociodemográficas, factores del donante y del receptor, estado al momento del trasplante y factores posteriores al trasplante que pudieran influir en la mortalidad. Finalmente se construyó un último modelo que incluyó los factores significativos asociados con la mortalidad en el primer año postrasplante con una $p<0,20$ en el

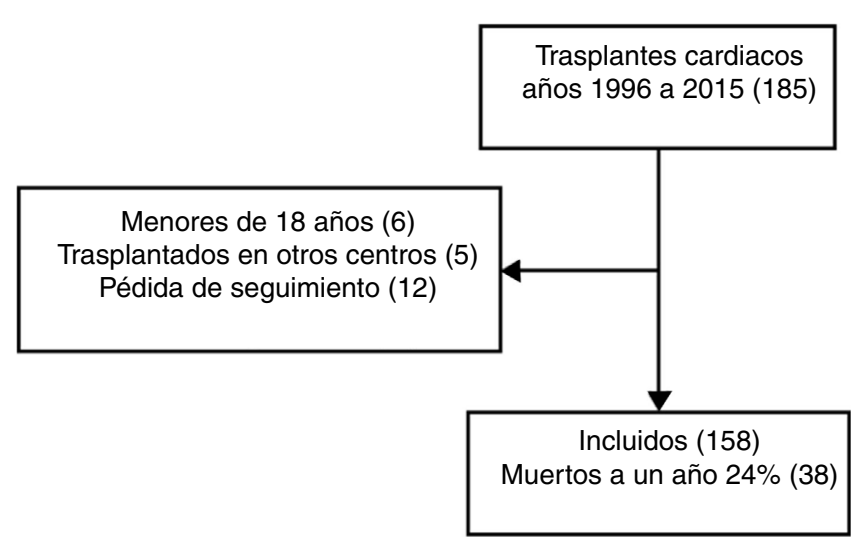

Figura 1 Flujograma de pacientes con trasplante cardiaco incluidos en el estudio.

modelo ajustado. Se realizó el diagnóstico del modelo de regresión.

Este estudio tuvo aprobación del comité institucional de ética en investigación biomédica y patrocinio de la Fundación Valle del Lili.

\section{Resultados}

Hubo 181 trasplantes cardíacos desde el año 1996 al 2015 (fig. 1). Se excluyeron 23 individuos menores de 18 años, trasplantados en otros centros y con pérdida en el seguimiento en el primer año.

\section{Características de los receptores}

Las características de los receptores al momento del trasplante de acuerdo con el estado vital al año de seguimiento se exponen en la tabla 1. La mayoría de los receptores fueron hombres, de raza mestiza, cuya mediana de edad fue mayor en los pacientes fallecidos en el primer año. Las principales etiologías de la falla cardiaca fueron miocardiopatía idiopática y cardiopatía isquémica. Se destacaron como comorbilidades la presencia de hipertensión arterial (43\%) y diabetes mellitus tipo 2 (17\%). De los pacientes que tenían un diagnóstico previo al trasplante de diabetes mellitus y antecedente de cirugía cardiaca previa el 55\% y 52\% fallecieron en el periodo evaluado, respectivamente. Adicionalmente, el $8 \%$ tenían historia de tromboembolia pulmonar, y $12 \%$ accidente cerebrovascular o accidente isquémico transitorio. Por otra parte, el $17 \%$ eran portadores de resincronizador cardiaco y $14 \%$ de cardiodesfibrilador implantable. Adicionalmente, se tuvieron en cuenta aquellos pacientes que durante el último año previo al trasplante requirieron algún método de soporte cardiorrespiratorio, como ventilación mecánica invasiva, uso de inotrópicos o vasoactivos; de los cuales el $28 \%$ y el $24 \%$ fallecieron en el primer año postrasplante, respectivamente.

\section{Características del donante}

Las características de los donantes se representan en la tabla 2 de acuerdo con el estado vital del receptor al año de seguimiento. La mediana de edad de los donantes fue 26,8 
Tabla 1 Características de los receptores de trasplante cardíaco

\begin{tabular}{|c|c|c|c|c|}
\hline Variables & $\begin{array}{l}\text { Total } \\
\mathrm{n}=158,(\%)\end{array}$ & $\begin{array}{l}\text { Vivos al año de } \\
\text { seguimiento } \\
n=120,(\%)\end{array}$ & $\begin{array}{l}\text { Fallecidos durante el } \\
\text { primer año postrasplante } \\
n=38,(\%)\end{array}$ & $\mathrm{p}$ \\
\hline Edad, años * & $50,0(39,5-57,2)$ & $49,1(38,2-56,0)$ & $52,2(45,3-58,4)$ & 0,053 \\
\hline Sexo masculino & $121(76,6)$ & $93(77,5)$ & $28(73,7)$ & 0,628 \\
\hline IMC $\left(\mathrm{kg} / \mathrm{m}^{2}\right)^{\text {*k* }}$ & $24,6 \pm 4,1$ & $24,5 \pm 4,2$ & $24,9 \pm 3,7$ & 0,518 \\
\hline Etnia & & & & 0,522 \\
\hline Mestizo & $138(87,5)$ & $104(87)$ & $34(89,5)$ & \\
\hline Afrodescendiente & $16(10)$ & $12(10)$ & $4(10,5)$ & \\
\hline Etiología de la falla cardiaca & & & & 0,106 \\
\hline Cardiopatía isquémica & $46(29)$ & $37(31)$ & $9(24)$ & \\
\hline Cardiopatía dilatada idiopática & $71(45)$ & $55(46)$ & $16(42)$ & \\
\hline Valvulopatía & $15(10)$ & $10(8)$ & $5(13)$ & \\
\hline Cardiopatía congénita & $2(1)$ & $0(0)$ & $2(5)$ & \\
\hline Otras causast & $24(15)$ & $18(15)$ & $6(16)$ & \\
\hline \multicolumn{5}{|l|}{ Comorbilidades } \\
\hline Diabetes mellitus & $27(17)$ & $12(10)$ & 15 (39) & 0,000 \\
\hline Hipertensión arterial & $69(43)$ & $48(40)$ & $21(55)$ & 0,098 \\
\hline ERC estadio 5 o diálisis & $6(4)$ & $2(2)$ & $4(11)$ & 0,062 \\
\hline Cirugía cardiaca previa & $21(13)$ & $10(8)$ & $11(29)$ & 0,001 \\
\hline Tabaquismo & $29(25)$ & $29(24)$ & $10(26)$ & 0,354 \\
\hline \multicolumn{5}{|l|}{ Protocolo pretrasplante } \\
\hline Creatinina, $\mathrm{mg} / \mathrm{dl}^{*}$ & $1,09(0,88-1,26)$ & $1,04(0,9-1,3)$ & $1,2(1,0-1,5)$ & 0,052 \\
\hline FEVI, \%* & $20(15-25)$ & $20(15-25)$ & $21,5(15-26,5)$ & 0,212 \\
\hline PAPm, mm Hg* & $33,7(21-42,3)$ & $31(16,7-41,3)$ & $38,5(29,6-44,7)$ & 0,019 \\
\hline Sin información & $15(9)$ & $11(9)$ & $4(10)$ & \\
\hline \multicolumn{5}{|l|}{ Soporte preoperatorio } \\
\hline Ventilación mecánica invasiva & $14(9)$ & $10(8)$ & $4(10)$ & 0,678 \\
\hline Uso de inotrópicos & $41(26)$ & $23(19)$ & $18(47)$ & \\
\hline Uso de vasoactivos & $18(11)$ & $12(10)$ & $6(16)$ & \\
\hline Sin información & $2(1)$ & $1(1)$ & $1(2)$ & \\
\hline
\end{tabular}

ERC: enfermedad renal crónica; FEVI: fracción de eyección del ventrículo izquierdo; IMC: índice de masa corporal; PAPm: presión media de la arteria pulmonar.

* Variables presentadas como medianas (rango intercuartílico);

** promedio (desviación estandar); Ł Otras causas: Cardiopatía hipertrófica, arritmia cardiaca, cardiopatía restrictiva, cardiopatía periparto, cardiopatía chagásica, cardiotoxicidad, cardiopatía por quimioterapia, cardiopatía infiltrativa, miocarditis viral.

años, siendo mayores aquellos fallecidos en el primer año de seguimiento. Aproximadamente, 9 de cada 10 donantes eran hombres, con una media de peso de $69,6( \pm 8,8)$ y la principal causa de muerte cerebral fue el trauma craneoencefálico, seguido de enfermedad cerebrovascular.

\section{Características del procedimiento quirúrgico}

Al momento del trasplante, el $64 \%$ de los pacientes se encontraban en lista de espera en estadio 1. Solamente un paciente requirió dispositivo de asistencia circulatoria (balón de contrapulsación aórtica) previo al procedimiento. La mediana de tiempo de isquemia fue 187 minutos (rango intercuartílico, RIC: 142-300) y el 20\% egresaron del procedimiento quirúrgico con tórax abierto. La mayoría de los trasplantes hechos tuvieron una relación donante hombre / receptor hombre (tabla 3 ).

\section{Seguimiento al mes, seis meses y al año}

Durante el seguimiento la complicación más frecuente fue infección en un $29 \%$, principalmente de las vías respiratorias $(n=30,33 \%)$ y bacteriemias $(n=16,18 \%)$. En segundo lugar, el $25 \%$ presentó rechazo celular agudo del injerto, teniendo en cuenta pacientes que presentaron rechazo celular $2 \mathrm{R} 0$ $3 \mathrm{R}$ según la clasificación de la Sociedad Internacional para trasplante de corazón y pulmón (ISHLT, su sigla en inglés).

\section{Mortalidad y factores de riesgo}

Se evidenció una supervivencia en el primer año de seguimiento postrasplante cardíaco del 76\%. La mayor mortalidad se presentó en el primer mes del trasplante (fig. 2), obteniéndose una mortalidad del $15,2 \%$ en este periodo $(n=24)$. La mortalidad al año de seguimiento postrasplante en aquellos pacientes que sobrevivieron al mes de fue del $11 \%$. Las principales causas de muerte fueron infecciones (29\%), 
Tabla 2 Características de los donantes de trasplante cardíaco

\begin{tabular}{|c|c|c|c|c|}
\hline \multirow[t]{2}{*}{ Variable } & Total & \multirow[t]{2}{*}{$\begin{array}{l}\text { Receptores vivos al año } \\
\text { post trasplante cardíaco }\end{array}$} & $\begin{array}{l}\text { Receptores fallecidos en } \\
\text { el año post trasplante } \\
\text { cardíaco }\end{array}$ & \multirow[t]{2}{*}{$\mathrm{p}$} \\
\hline & $\mathrm{n}=158,(\%)$ & & $\mathrm{n}=38,(\%)$ & \\
\hline Edad, años* & $26(20-33)$ & $26(20-33)$ & $24(19,5-37)$ & 0,861 \\
\hline Sin información & $8(5)$ & $7(6)$ & $1(3)$ & \\
\hline Sexo masculino & $139(88)$ & $107(89)$ & $32(84)$ & 0,181 \\
\hline Sin información & $8(5)$ & $7(6)$ & $1(3)$ & \\
\hline$I M C(\mathrm{~kg} / \mathrm{m} 2)^{*}$ & $24,2(22,9-25,4)$ & $24,2(23,0-25,6)$ & $23,9(22,3-24,6)$ & 0,097 \\
\hline Sin información & $31(20)$ & $26(22)$ & $5(13)$ & \\
\hline \multicolumn{2}{|c|}{ Causa primaria de muerte cerebral } & & & 0,201 \\
\hline Cerebrovascular & $21(13)$ & $13(11)$ & $8(21)$ & \\
\hline Trauma & $121(77)$ & $95(79)$ & $26(68)$ & \\
\hline \multicolumn{5}{|l|}{ craneoencefálico } \\
\hline Tumor SNC & $2(1)$ & $1(1)$ & $1(3)$ & \\
\hline Otra & $2(2)$ & $1(1)$ & $1(3)$ & \\
\hline Sin información & $12(7)$ & $10(8)$ & $2(5)$ & \\
\hline
\end{tabular}

IMC: índice de masa corporal; SNC: sistema nervioso central.

* variables presentadas como mediana (rango intercuartílico)

Tabla 3 Caracteristicas del procedimiento quirúrgico

\begin{tabular}{|c|c|c|c|c|}
\hline Variable & $\begin{array}{l}\text { Total } \\
\mathrm{n}=158,(\%)\end{array}$ & $\begin{array}{l}\text { Vivos al año de } \\
\text { seguimiento } \\
n=120,(\%)\end{array}$ & $\begin{array}{l}\text { Fallecidos durante el } \\
\text { primer año postrasplante } \\
\mathrm{n}=38(\%)\end{array}$ & Valor de $p$ \\
\hline Prioridad del trasplante & & & & 0.003 \\
\hline Estadio $0 \mathrm{~A}$ & 30 (19) & 17 (14) & $13(34)$ & \\
\hline Estadio $\mathrm{OB}$ & $26(16)$ & 17 (14) & $9(24)$ & \\
\hline Estadio 1 & $102(65)$ & $86(72)$ & $16(42)$ & \\
\hline Edad donante $>$ receptor & $11(7)$ & $9(7)$ & $2(5)$ & \\
\hline Sin información & $8(5)$ & $7(6)$ & $1(3)$ & \\
\hline Relación receptor/donante & & & & 0,134 \\
\hline Hombre/Mujer & $2(1)$ & $0(0)$ & $2(5)$ & \\
\hline Hombre/Hombre & $105(66)$ & $81(67)$ & $24(63)$ & \\
\hline Mujer/Hombre & 27 (17) & $20(16)$ & $7(18)$ & \\
\hline Mujer/Mujer & $16(10)$ & $12(10)$ & $4(11)$ & \\
\hline Sin información & $8(5)$ & $7(6)$ & $1(3)$ & \\
\hline $\begin{array}{l}\text { Tiempo de isquemia }>150 \\
\text { minutos }\end{array}$ & $112(71)$ & $77(64)$ & $35(92)$ & 0,001 \\
\hline Sin información & $1(0.6)$ & $1(0.8)$ & & \\
\hline Período del trasplante & & & & 0,584 \\
\hline $1996-2000$ & $29(18)$ & $24(20)$ & $5(13)$ & \\
\hline $2001-2005$ & $33(21)$ & $26(22)$ & $7(18)$ & \\
\hline $2006-2010$ & $57(36)$ & $40(33)$ & $17(45)$ & \\
\hline $2011-2015$ & $39(25)$ & $30(25)$ & $9(24)$ & \\
\hline
\end{tabular}

seguido de falla multiorgánica (24\%) y fallo primario del injerto (13\%). En el análisis multivariado (tabla 4) se encontró significancia estadística para mortalidad en el primer año para la etiología de falla cardíaca por cardiopatía congénita, antecedente de cirugía cardiaca previa, diabetes mellitus pretrasplante, tiempo de isquemia mayor a 150 minutos y relación receptor hombre con donante mujer, mientras que, el encontrarse en estadio 1 en lista de espera fue un factor protector de mortalidad (tabla 4).

\section{Discusión}

El trasplante cardíaco es la última opción terapéutica para el manejo de aquellos pacientes con síndrome de falla cardíaca 

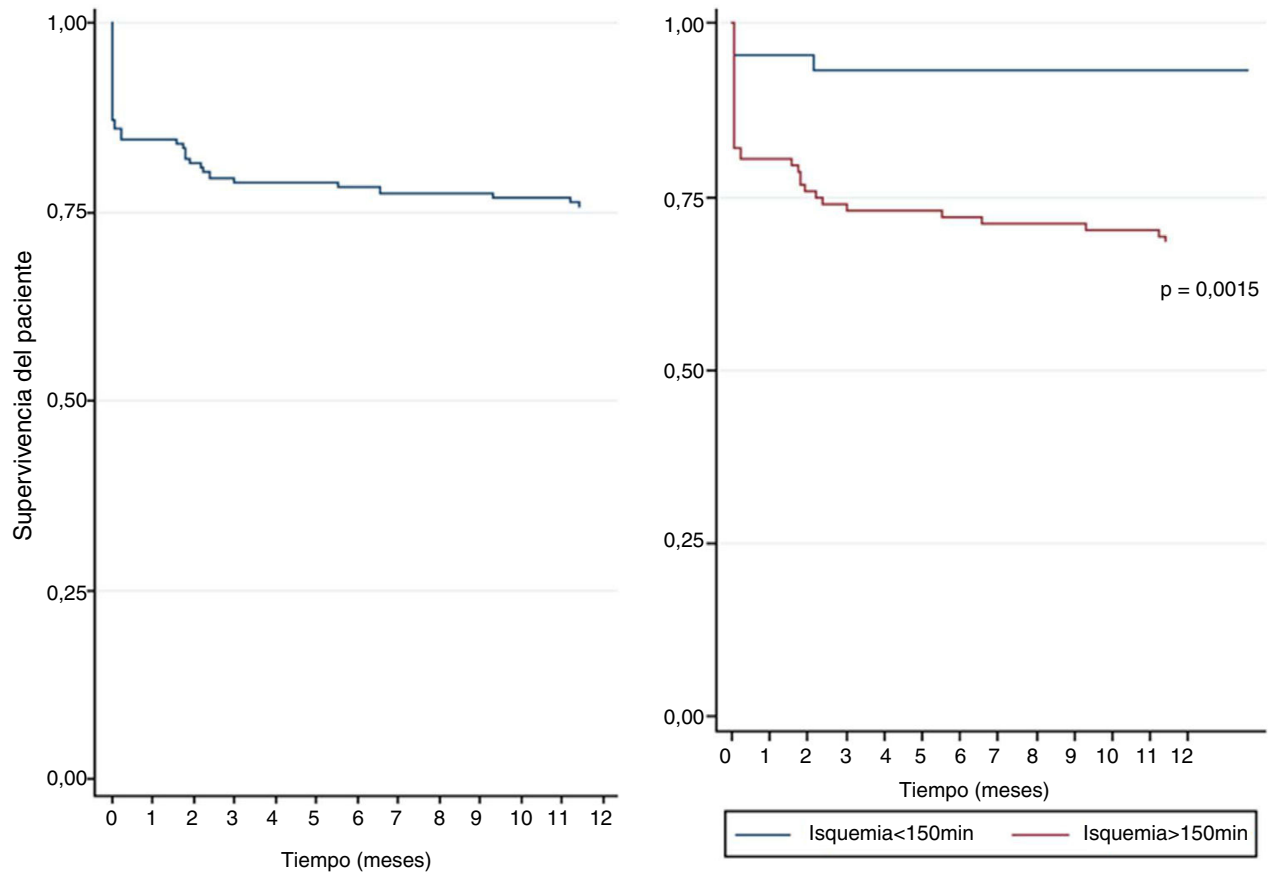

Figura 2 Curva de sobrevida de Kaplan Meier de los trasplantes cardiacos de 1996-2005 en el primer año de seguimiento. A la derecha la sobrevida de todos los pacientes a 12 meses de seguimiento, a la izquierda la sobrevida condicionada con el tiempo de isquemia menor y mayor de 150 minutos.

Tabla 4 Factores asociados a la mortalidad en el primer año postrasplante

\begin{tabular}{|c|c|c|c|c|c|c|}
\hline \multirow[t]{2}{*}{ Variable } & \multicolumn{3}{|c|}{ Bivariado } & \multicolumn{3}{|c|}{ Multivariado } \\
\hline & Hazard ratio & IC (95\%) & $\mathrm{p}$ & Hazard ratio & IC (95\%) & $\mathrm{p}$ \\
\hline Receptor masculino & 0,84 & $0,41-1,72$ & 0,629 & 0,33 & $0,08-1,37$ & 0,125 \\
\hline Edad del receptor & 1,02 & $0,95-1,11$ & 0,548 & 1,02 & $0,98-1,06$ & 0,205 \\
\hline \multicolumn{7}{|l|}{ Etilogía de la falla cardiaca } \\
\hline $\begin{array}{l}\text { Cardiopatía dilatada } \\
\text { idiopática }\end{array}$ & 1,19 & $0,52-2,69$ & 0,676 & 2,89 & $1,03-8,12$ & 0,044 \\
\hline Valvulopatía & 1,86 & $0,62-5,54$ & 0,267 & 1,92 & $0,51-7,16$ & 0,333 \\
\hline Cardiopatía congénita & 10,55 & $2,20-50,63$ & 0,003 & 21,62 & $2,08-224,77$ & 0,01 \\
\hline Otra causa de falla cardiaca & 1,31 & $0,47-3,69$ & 0,606 & 5,56 & $1,60-19,37$ & 0,007 \\
\hline \multicolumn{7}{|l|}{ Comorbilidades } \\
\hline Diabetes mellitus & 3,72 & $1,94-7,16$ & 0,000 & 4,64 & $1,92-11,21$ & 0,001 \\
\hline $\begin{array}{l}\text { Creatinina pretrasplante } \\
(\mathrm{mg} / \mathrm{dl})\end{array}$ & 1,14 & $0,97-1,35$ & 0,112 & 1,15 & $0,96-1,40$ & 0,136 \\
\hline \multicolumn{7}{|c|}{ Prioridad del trasplante al momento del llamado } \\
\hline Estadio OB & 0,84 & $0,36-1,96$ & 0,685 & 0,74 & $0,26-2,12$ & 0,581 \\
\hline Estadio 1 & 0,33 & $0,16-0,68$ & 0,003 & 0,25 & $0,10-0,60$ & 0,002 \\
\hline \multicolumn{7}{|l|}{ Relación receptor/donante } \\
\hline $\begin{array}{l}\text { Receptor Hombre/ Donante } \\
\text { Mujer }\end{array}$ & 6,79 & $1,59-28,98$ & 0,010 & 9,2 & $1,63-51,81$ & 0,012 \\
\hline $\begin{array}{l}\text { Receptor Mujer/ Donante } \\
\text { Hombre }\end{array}$ & 1,11 & $0,49-2,55$ & 0,795 & 0,37 & $0,08-1,75$ & 0,214 \\
\hline Cirugía cardiaca previa & 3,22 & $1,59-6,52$ & 0,001 & 17,76 & $1,47-213,88$ & 0,023 \\
\hline Tiempo de isquemia $>150 \mathrm{~min}$ & 5,21 & $1,60-16,96$ & 0,006 & 5,41 & $1,22-24,08$ & 0,026 \\
\hline $\begin{array}{l}\text { Cirugía cardiaca previa y } \\
\text { tiempo de isquemia }>150 \\
\text { min }\end{array}$ & - & - & - & 16,07 & $2,96-87,38$ & 0,001 \\
\hline
\end{tabular}

IC: intervalo de confianza. 
que persisten sintomáticos a pesar de tratamiento médico y quirúrgico óptimos. Este ha demostrado tener un impacto significativo en la supervivencia, el estado funcional y la calidad de vida de los pacientes ${ }^{1,4}$. Se ha reportado una mediana de supervivencia de 11,2 años y 14,1 años condicionada al superar el primer mes postrasplante cardíaco, siendo este el período con mayor tasa de mortalidad $^{5}$.

En este estudio se encontró una mortalidad en el primer año de seguimiento postrasplante del 24\%, similar a lo reportado por el Registro Español de Trasplante Cardiaco XxVII $(1984-2015)^{6}$. Sin embargo, al compararla con el reporte de 2014 de la ISHLT fue ligeramente mayor, siendo en esta de un $19 \%^{3}$. Entre las causas más comunes de mortalidad se describen las infecciones principalmente de origen respiratorio, que pueden estar relacionadas con la necesidad de mayor dosis de inmunosupresores para el control de la respuesta inmune, seguido por la falla del injerto y rechazo agudo, lo cual es comparable a lo observado en nuestra cohorte $^{7,8}$.

Se ha reportado una correlación entre ciertas características propias del donante, del receptor y del procedimiento quirúrgico con la mortalidad en el primer año postrasplante. Según el Registro del ISHLT los principales factores son: donante de sexo femenino con receptor masculino, uso de ventilación mecánica invasiva pretrasplante, falla renal pretrasplante con requerimiento de hemodiálisis del receptor, edad aumentada del donante, tiempo de isquemia mayor a 200 minutos, enfermedad cardiaca congénita como causa del trasplante y retrasplante cardíaco ${ }^{9,10}$. Respecto a lo anterior, los resultados de esta investigación fueron coherentes con lo reportado en la literatura, encontrándose como factores de riesgo la etiología de falla cardíaca por cardiopatía congénita, el antecedente de diabetes mellitus, cirugía cardiaca previa, la relación receptor hombre con donante mujer y el tiempo de isquemia mayor a 150 minutos.

\section{Cardiopatía congénita}

El 3\% de los adultos que se someten a trasplante cardiaco tienen cardiopatía congénita como una indicación para el trasplante. El diagnóstico de cardiopatía congénita como etiología de la falla cardiaca se ha reportado en varios estudios como un factor de riesgo para mortalidad posterior al trasplante cardiaco, que podría ser explicado por los cambios irreversibles en la vasculatura pulmonar, mayor riesgo de sangrado secundario a intervenciones quirúrgicas previas y compromiso concomitante de varios órganos ${ }^{11,12}$. En nuestra cohorte se realizaron dos trasplantes a pacientes con antecedente de cardiopatía congénita y ambos fallecieron en el primer año de seguimiento, lo cual demostró ser factor de riesgo. En un estudio llevado a cabo por Patel et al. a partir del registro "Red unida para compartir órganos" (UNOS, su sigla en inglés) desde 1987 hasta 2006, encontraron que el trasplante cardiaco para los pacientes con cardiopatía congénita tiene una mortalidad a treinta días estadísticamente significativa respecto a aquellos pacientes cuya etiología de la falla cardiaca fue diferente, sin embargo, no hallaron diferencia en la mortalidad a largo plazo $^{12}$.

\section{Diabetes mellitus}

Los pacientes con diabetes previa al trasplante tienen tasa de supervivencia menor, pues se ha encontrado que tienen mayor riesgo para el desarrollo de infecciones y de falla renal, los cual podría deberse al uso conjunto de terapia inmunosupresora y corticosteroides, lo que dificulta un control glucémico óptimo ${ }^{13,14}$.

Un estudio realizado por Russo et al. planteó que los pacientes no diabéticos tienen mejor supervivencia en comparación con los diabéticos; pese al clasificar este último grupo según la severidad de acuerdo con las diferentes complicaciones o comorbilidades (accidente cerebrovascular, insuficiencia renal, enfermedad vascular periférica y obesidad mórbida), el grupo con ausencia de estos factores no mostró diferencia significativa en cuanto a la supervivencia en comparación con los no diabéticos ${ }^{15}$. En el presente estudio se observó que la supervivencia se ve afectada de forma negativa por diabetes mellitus previo al trasplante; sin embargo, no se tuvo en cuenta la terapia inmunosupresora recibida ni se encontró asociación con otras comorbilidades. Por el contrario, estudios como el de Moro et al., describen que no existe impacto negativo en la supervivencia entre la presencia de diabetes mellitus previa al trasplante, así como en aquellos que la desarrollan posterior a este ${ }^{16}$.

\section{Cirugía cardiaca previa}

De igual forma, se ha descrito que la cirugía cardiaca previa puede contribuir a peores desenlaces asociado a la distorsión de la anatomía. Por nuestra parte evidenciamos que este factor influye en la mortalidad precoz y al primer año de seguimiento, en contraste a lo evidenciado por Aziz y colaboradores, quienes evaluaron en su estudio dos grupos de pacientes, aquellos con historia de cirugía cardiaca previa y pacientes cuyo trasplante correspondió a la primera intervención cardiaca, encontrando tiempos de isquemia prolongados y mayor sangrado postoperatorio en el primer grupo; sin embargo, los resultados a largo plazo fueron similares en ambos grupos, sin obtener diferencias significativas en la mortalidad al año, dos años y 5 años de seguimiento ${ }^{17}$.

\section{Receptor hombre/donante mujer}

El sexo femenino se ha considerado un factor de riesgo importante para el rechazo y la infección posterior al trasplante, presentando una menor supervivencia en el primer año, en comparación con los hombres ${ }^{18,19}$. No obstante, no se halló diferencia entre los dos géneros para mortalidad en nuestro estudio. De igual forma, se ha reportado que la discrepancia entre el sexo del donante y el receptor juega un papel importante en el desenlace, principalmente cuando se realiza trasplantes con receptor hombre y donante mujer. En nuestra investigación se encontró que hombres receptores de mujeres donantes tuvieron mayor riesgo de muerte en el primer año. Weber y colaboradores, compararon cuatro grupos dependiendo del sexo del donante y receptor, encontrando que la discrepancia de sexo aumenta significativamente el número de rechazos celulares agudos, reduce el aclaramiento de creatinina y reduce la supervivencia en el primer año postrasplante ${ }^{20}$. 
Del mismo modo, Khush y cols., se basaron en el registro de trasplante cardiaco de la ISHLT encontrando que los receptores hombres de donantes mujeres tienen $10 \%$ mayor riesgo de mortalidad ajustada comparada con receptores hombres de donantes hombres, con mejores resultados en mujeres donantes con receptores mujeres ${ }^{21}$.

\section{Tiempo de isquemia}

Por otra parte, se ha establecido que un tiempo de isquemia óptimo es aquel menor de 180 minutos y prolongado cuando es mayor a 240 minutos $^{22}$. Factores como: el centro de rescate del órgano, el transporte hasta el lugar de trasplante, cirugía cardiaca previa y la técnica quirúrgica; pueden influir en un tiempo de isquemia prolongado ${ }^{23}$.

En este caso, al tratarse de un centro de referencia del suroccidente del país, se realizan trasplantes de órganos rescatados en otros centros a nivel local y nacional, encontrándose que tiempos de isquemia mayores de 150 minutos aumenta el riesgo de mortalidad en el primer año postrasplante. Russo et al. realizaron un estudio basado en el registro UNOS, y concluyeron que el efecto del tiempo de isquemia prolongado (mayor a 4 horas) está relacionado con la edad del receptor y mejor tolerancia en aquellos receptores más jóvenes ${ }^{24}$. Se ha establecido que tiempos mayores de 200 minutos se relacionan con mayor uso de inotrópicos en las primeras 48 horas, reducción de la fracción de eyección del ventrículo izquierdo en el postoperatorio, estancia hospitalaria prolongada, disfunción del injerto y disminución de la capacidad funcional postoperatoria temprana de los receptores ${ }^{23,25-27}$.

Una de las principales limitaciones es que se trató de un estudio retrospectivo, en el cual la forma de recolección de la información tanto del donante como del receptor antes del 2011 se encontraba en registros médicos en medio físico, los cuales no tuvieron disponibles todas las variables incluidas en el estudio. Por lo anterior, algunas variables que pudieron influir en el modelo de regresión y que pudieran tener relación con la mayor mortalidad fueron retiradas del análisis multivariado, por esto se evitó incluir variables con datos faltantes en más del $20 \%$ de la muestra. Adicionalmente, se trata de un estudio en el que los datos fueron obtenidos de una única institución con un tamaño pequeño de muestra.

\section{Conclusión}

En individuos que se sometieron a un trasplante cardíaco los principales determinantes de mortalidad en el primer año de seguimiento posterior al trasplante cardiaco fueron la etiología de falla cardíaca por cardiopatía congénita, el antecedente de diabetes mellitus, la cirugía cardiaca previa, la relación receptor hombre con donante mujer y el tiempo de isquemia del órgano mayor a 150 minutos.

\section{Financiación}

El presente estudio no recibió ninguna ayuda económica específica de agencias de financiamiento en los sectores público, comercial o sin fines de lucro.

\section{Conflictos de interés}

\author{
Ninguno.
}

\section{Bibliografía}

1. Yancy CW, Jessup M, Bozkurt B, Butler J, Casey DE Jr, Drazner MH, et al. 2013 ACCF/AHA guideline for the management of heart failure: a report of the American College of Cardiology Foundation/American Heart Association Task Force on Practice Guidelines. J Am Coll Cardiol. 2013;62:e147-239.

2. Yusen RD, Christie JD, Edwards LB, Kucheryavaya AY, Benden C, Dipchand Al, et al. The Registry of the International Society for Heart and Lung Transplantation: Thirtieth Adult Lung and Heart-Lung Transplant Report-2013; focus theme: age. J Heart Lung Transplant. 2013;32:965-78.

3. Yusen RD, Edwards LB, Kucheryavaya AY, Benden C, Dipchand Al, Dobbels F, et al. The registry of the International Society for Heart and Lung Transplantation: thirty-first adult lung and heart-lung transplant report-2014; focus theme: retransplantation. J Heart Lung Transplant. 2014;33:1009-24.

4. Eisen HJ. Heart Failure. An Issue of Cardiology Clinics. Elsevier Health Sciences;. 2014:610.

5. González-Vílchez F, Gómez-Bueno M, Bonet LA, Crespo-Leiro MG. Registro Español de Trasplante Cardiaco (Adultos). xxv Informe Oficial de la Sección de Insuficiencia Cardiaca y Trasplante Cardiaco de la Sociedad Española de Cardiología (1984-2013). Revista Española de Cardiología Suplementos. 2015;15:31-42.

6. González-Vílchez F, Cubero JS, Almenar L, Crespo-Leiro MG, Arizón JM, Sousa I, et al. Registro Español de Trasplante Cardiaco. xxvii Informe Oficial de la Sección de Insuficiencia Cardiaca y Trasplante Cardiaco de la Sociedad Española de Cardiología (1984-2015). Rev Esp Cardiol. 2016;69:1071-82.

7. Luckraz H, Goddard M, Charman SC, Wallwork J, Parameshwar J, Large SR. Early mortality after cardiac transplantation: Should we do better? J Heart Lung Transplant. 2005;24:401-5.

8. Wilhelm MJ. Long-term outcome following heart transplantation: current perspective. J Thorac Dis. 2015;7:549-51.

9. Yusen RD, Edwards LB, Kucheryavaya AY, Benden C, Dipchand Al, Goldfarb SB, et al. The Registry of the International Society for Heart and Lung Transplantation: Thirty-second Official Adult Lung and Heart-Lung Transplantation Report-2015; Focus Theme: Early Graft Failure. J Heart Lung Transplant. 2015;34:1264-77.

10. Stehlik J, Edwards LB, Kucheryavaya AY, Benden C, Christie JD, Dipchand Al, et al. The Registry of the International Society for Heart and Lung Transplantation: $29^{\text {th }}$. official adult heart transplant report-2012. J Heart Lung Transplant. 2012;31:1052-64.

11. John R, Rajasinghe HA, Chen JM, Weinberg AD, Sinha P, Mancini DM, et al. Long-term outcomes after cardiac transplantation: an experience based on different eras of immunosuppressive therapy. Ann Thorac Surg. 2001;72:440-9.

12. Patel ND, Weiss ES, Allen JG, Russell SD, Shah AS, Vricella LA, et al. Heart transplantation for adults with congenital heart disease: analysis of the United network for organ sharing database. Ann Thorac Surg. 2009;88:814-21, discussion 821-2.

13. Marelli D, Laks H, Patel B, Kermani R, Marmureanu A, Patel J, et al. Heart transplantation in patients with diabetes mellitus in the current era. J Heart Lung Transplant. 2003;22:1091-7.

14. Klingenberg R, Gleissner C, Koch A, Schnabel PA, Sack F-U, Zimmermann R, et al. Impact of pre-operative diabetes mellitus upon early and late survival after heart transplantation: a possible era effect. J Heart Lung Transplant. 2005;24:1239-46.

15. Russo MJ, Chen JM, Hong KN, Stewart AS, Ascheim DD, Argenziano $M$, et al. Survival after heart transplantation is 
not diminished among recipients with uncomplicated diabetes mellitus. Circulation. 2006;114:2280-7.

16. Moro JA, Martínez-Dolz L, Almenar L, Martínez-Ortiz L, Chamorro C, García C, et al. Impact of diabetes mellitus on heart transplant recipients. Rev Esp Cardiol. 2006;59:1033-7.

17. Aziz T. Early and long-term results of heart transplantation after previous cardiac surgery. Eur J Cardiothorac Surg. 2000;17:349-54.

18. Salehi M, Bakhshandeh AR, Latifi S, Rahmanian M. Heart transplant survival rate in Iran: a single-center registry report. Asian Cardiovasc Thorac Ann. 2014;22:534-8.

19. Almenar L. Influencia del sexo en la mortalidad por trasplante cardiaco: subanálisis del Registro Español de Trasplante Cardiaco. Revista Española de Cardiología Suplementos. 2008;8:49D-54D.

20. Weber DJ, Didolkar P, Gracon A, Hellman Y, Hadi MA, Malik A, et al. The Role of Donor Age and Gender on Survival after Heart Transplantation. J Heart Lung Transplant. 2014;33:S63.

21. Khush KK, Kubo JT, Desai M. Influence of donor and recipient sex mismatch on heart transplant outcomes: Analysis of the International Society for Heart and Lung Transplantation Registry. J Heart Lung Transplant. 2012;31:459-66.

22. Crespo Leiro MG, Bonet LA, Alonso-Pulpón L, Campreciós M, Cuenca Castillo JJ, de la Fuente Galván L, et al. Conferencia de Consenso de los Grupos Españoles de Trasplante Cardiaco. Revista Española de Cardiología Suplementos. 2007;7, 4B-54B.

23. Yağdı T. The effect of donor ischemic time on mortality in heart transplanted patients. Turkish Journal of Thoracic and Cardiovascular Surgery. 2014;22:241-6.

24. Russo MJ, Chen JM, Sorabella RA, Martens TP, Garrido M, Davies RR, et al. The effect of ischemic time on survival after heart transplantation varies by donor age: an analysis of the United Network for Organ Sharing database. J Thorac Cardiovasc Surg. 2007; 133:554-9.

25. Schnitzler MA, Buchanan PM, Burroughs TE, Lee R, Hauptman PJ. 9: Impact of ischemia time on the outcomes of heart transplant. J Heart Lung Transplant. 2007;26:S64.

26. Morgan JA, John R, Weinberg AD, Kherani AR, Colletti NJ, Vigilance DW, et al. Prolonged donor ischemic time does not adversely affect long-term survival in adult patients undergoing cardiac transplantation. J Thorac Cardiovasc Surg. 2003;126:1624-33.

27. Buendía-Fuentes F, Almenar-Bonet L, Martínez-Dolz L, SánchezLázaro I, Rodríguez-Serrano M, Domingo-Valero D, et al. Ischemic time as a predictor of physical recovery in the first months after heart transplantation. ISRN Cardiol. 2012;2012:907102. 